\title{
XÁC ĐỊNH MỨC ĐỘ NHIỄM MẶN TẦNG ĐẤT MẶT CANH TÁC NÔNG NGHIỂP Ở MộT SỐ VÙNG GẦN CỬA SÔNG VEN BIỄN HẢI PHÒNG - THÁI BìNH BĂNG ẢNH VIỄN THÁM SENTINEL 2A
}

\author{
LÊ TH!̣ THU HIỀN(1), PHẠM MINH HẢI ${ }^{(2)}$, \\ NGUYẼ̃N THANH BİNH(1), NGUYẼ̃N NGOC THẮNG ${ }^{(1)}$ \\ (1)Viện Địa lý, Viện Hàn lâm Khoa học và Công nghệ Việt Nam \\ ${ }^{(2)}$ Viện Khoa học Đo đạc và Bản đồ
}

\section{Tóm tắt:}

Nghiên cưu này đánh giá độ nhiễm mặn tầng đất mặt canh tác nông nghiệp ở vùng cửa sông ven biển Hải Phòng-Thái Bình sư dụng tu liệu Sentinel 2A. Dũ liệu Sentinel $2 A$ auợc sử dụng để chiết suất các chi số, bao gồm: các kênh phổ đơn, chi số VSSI, chi số SAVI, chỉ số NDVI và chỉ số NDSI. Các phân tích thống kê giữa độ dẫn điện $\left(E C_{1: 5}, d S / m\right)$ và các chỉ số đã được thực hiện. Kết quả chỉ ra rằng các giá trị phổ của dải hồng ngoại gần NIR và chi số VSSI tuoơng quan tốt với EC 1:5 $_{\text {(vói }}$ hệ số tuoong quan tuơng ứng là 0,75 và 0,63). Kết quả so sánh cho thấy độ mặn của đất uớc tính tì dĩ liệu Sentinel $2 A$ phù hợp với dũ liệu thục địa (với $R^{2}=0,74$ và $R M S E=3,36 \mathrm{dS} / \mathrm{m}$ đối với kênh phổ NIR và $R^{2}=0,67$ và $R M S E=3,8 \mathrm{dS} / \mathrm{m}$ đối với chỉ số VSSI). Các kết quả của nghiên cúu này chứng minh rằng dũ liệu Sentinel $2 A$ có tiềm năng cao trong việc giám sát độ mặn của lớp đất bề mặt. Kết quả của nghiên cưu hưu ích cho các hoạt động nông nghiệp, cung cấp thông tin quan trọng cho chính quyền và nông dân bằng cách lạp bản đồ độ mặn của đất làm cơ sở lựa chon tốt hơn các loại cây trồng để giảm tổn thất kinh tế trong bối cảnh biến đổi khi hậu.

\section{Mở đầu}

Nhiễm mặn đất là một tai biến động, có thể xảy ra thông qua một quá trình tự nhiên (nhiễm mặn do nước biển dâng) hoặc là kết quả của các hoạt động nhân sinh (nhiễm mặn thứ cấp do đô thị hóa hoặc tưới tiêu), quá trình làm giàu đất có muối hòa tan đến mức có hại ở hoặc gần bề mặt đất (Metternicht, 2008). Do các tác động tàn phá của nhiễm mặn đối với độ phì nhiêu của đất và sản xuất nông nghiệp, việc tìm cách giảm thiểu các tác động tiêu cực đến đất là rất cần thiết. Một bước quan trọng là lập bản đồ phạm vi không gian nhiễm mặn và phân loại mức độ mặn trong các khu vực bị ảnh hưởng là nhiệm vụ quan trọng để các nhà quản lý lên kế hoạch nông nghiệp bền vững (Dehni và Lounis, 2012).

Nhiều phương pháp khác nhau đã được phát triển để ứng dụng ảnh viễn thám cho nghiên cứu độ mặn của đất như phản xạ quang phổ, phân tích thống kê, mô hình toán học và đo đạc địa vật lý (Fernandez-Buces, 2006). Trong các bộ cảm vệ tinh và kỹ thuật phân tích đã được sử dụng để thành lập bản đồ độ mặn của đất và bản đồ độ dẫn điện (EC) thì kỹ thuật phân tích viễn thám đa phổ có quy mô phát triển rộng rãi nhất và được xem là công cụ hữu ích cho hướng nghiên cứu này (Richards, 1954). Verma (1994) đã sử dụng tư liệu viễn thám Landsat TM để nghiên cứu sự ô nhiễm đất và thấy rằng mức độ ô nhiễm của đất do mặn ảnh hưởng đến đặc điểm che phủ đất, dẫn đến các hình thái đất khác nhau (màu sắc, kết cấu, hình dạng, v.v.). Trong hầu hết các trường hợp, nhiều kênh phổ được chuyển thành một chỉ số có mức độ nhạy cảm cao với độ mặn của đất hơn so với một kênh phổ đơn lẻ (Madani, 2005). Kết quả của các nghiên cứu này đều cho thấy khả năng lập bản đồ độ mặn khi sử dụng dữ

Ngày nhận bài: 05/07/2020, ngày chuyển phản biện: 09/07/2020, ngày chấp nhận phản biện: 15/07/2020, ngày chấp nhận đăng: 18/07/2020 
liệu vệ tinh quang học như Landsat hay Sentinel nắng.

$2 \mathrm{~A}$.

Ở Việt Nam, các nghiên cứu chủ yếu áp dụng các mô hình thủy văn để nghiên cứu xâm nhập mặn trên các vùng cửa sông ven biển, trong đó một số nghiên cứu cũng tích hợp viễn thám và GIS với nội dung lấp đầy/nội suy số liệu và hiệu chỉnh mô hình, các nghiên cứu liên quan đến sử dựng ảnh viễn thám đánh giá nhiễm mặn đất còn rất hạn chế.

Nhìn chung, những nghiên cứu về độ mặn của đất ở vùng đồng bằng ven biển chưa được thực hiện nhiều, nơi ảnh hưởng thủy triều và mực nước biển. Do đó, nghiên cứu này sẽ sử dụng dữ liệu mẫu đất kết hợp với tư liệu Sentinel $2 \mathrm{~A}$ để đánh giá độ mặn của đất ở khu vực ven biển ĐBSH.

\section{Phương pháp và khu vực nghiên cứu}

\subsection{Khu vẹc nghiên cúu}

Khu vực nghiên cứu là vùng ven biển Hải Phòng - Thái Bình (Hình 1), với các điểm nghiên cứu ở các vùng đất canh tác nông nghiệp, gồm cả một số khu vực bị nhiễm mặn nặng do ảnh hưởng của sản xuất muối và nuôi trồng thủy sản.

\subsection{Tu liệu nghiên cứu}

\section{a) Dũ liêu vê tinh}

Nghiên cứu sử dụng dữ liệu ảnh vệ tinh Sentinel 2A độ phân giải $10 \mathrm{~m}$ chụp ngày 2/11/2018. Ảnh được thu thập để sử dụng trong nghiên cứu là ảnh được lựa chọn vào thời điểm thời tiết tốt, độ che phủ mây dưới $20 \%$ và gần với thới điểm lấy mẫu ngoài thực địa.

\section{b) Dĩ liêu thuc đia}

Dữ liệu thực địa về độ mặn mặt đất được thu thập bằng cách lấy mẫu đất theo hai đợt vào ngày $20-21 / 1$ và 2-3/11/2018, với tổng cộng 79 mẫu đất. Vị trí của các mẫu được chọn dựa trên bản đồ đất để đáp ứng yêu cầu các mẫu được đặt tại các loại đất khác nhau và phân bố đều trên toàn bộ khu vực nghiên cứu (Hình 2). Các mẫu đất được lấy tại hiện trường ở độ sâu từ 0 đến $20 \mathrm{~cm}$ và trong điều kiện thời tiết không có mưa, có

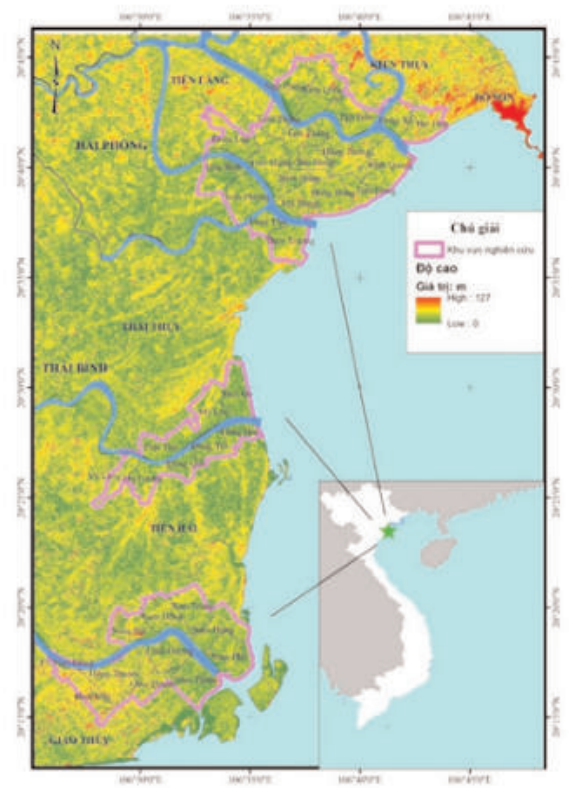

Hình 1: Vị trí khu vục nghiên cúu

Các mẫu đất sau đó được phân tích để xác định độ dẫn điện của đất $\mathrm{EC}_{1: 5}$ (Richards, 1954) theo Tiêu chuẩn Việt Nam TCVN 6650:2000 do Bộ Khoa học Công nghệ ban hành với nguyên tắc: Chiết các mẫu đất được làm khô trong không khí bằng nước ở nhiệt độ $20^{\circ} \mathrm{C} \pm 1^{\circ} \mathrm{C}$ theo tỷ lệ chiết $1: 5(\mathrm{~m} / \mathrm{V})$, để hoà tan các chất điện phân. Đo độ dẫn điện riêng của dịch chiết đã lọc và kết quả được hiệu chỉnh đến nhiệt độ $25^{\circ} \mathrm{C}$. Trong tổng số 79 mẫu, 50 mẫu được sử dụng để xây dựng hàm tương quan giữa ảnh vệ tinh và $\mathrm{EC}_{1: 5}$ và 29 mẫu được sử dụng để đánh giá độ chính xác và hiệu chỉnh mô hình.

\subsection{Phuơng pháp nghiên cúu}

\section{a) Tiền xủ lý ảnh vê tinh:}

Ảnh vệ tinh Sentinel-2A vùng nghiên cứu đã được hiệu chỉnh hình học và bức xạ trước khi đến tay người sử dụng nên trong nghiên cứu này ảnh chỉ cần được hiệu chỉnh khí quyển trong phần mềm ENVI 5.3 theo các phương pháp FLAASH:

$$
L=\left(\frac{A_{\rho}}{1-\rho_{e} S}\right)+\left(\frac{B \rho_{e}}{1-\rho_{e} S}\right)+L_{a}
$$




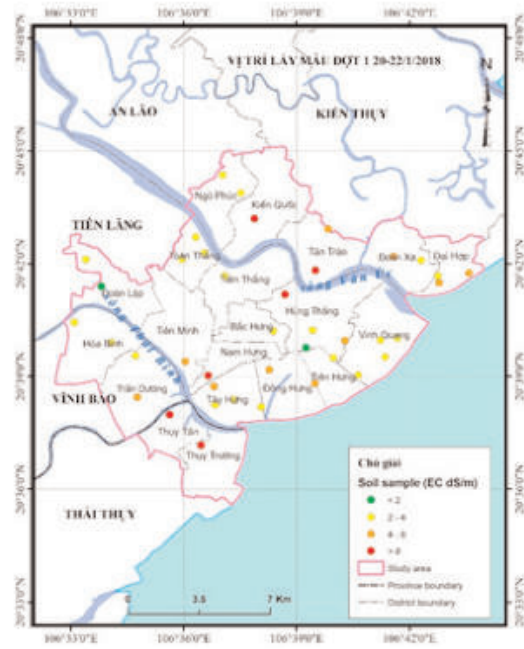

Hình 2: Vị trí lấy mẫu đất đơt 1 ngày

Trong đó: $\rho$ - giá tri phản xạ phổ trên bề mặt đất; $\rho_{e}$ - giá trị phản xạ phổ trung bình; $\mathrm{S}$ - suất phản chiếu của khí quyển; $L_{a}$ - giá trị bức xạ điện từ bị tán xạ trở lại bởi khí quyển; $\mathrm{A}$ và $\mathrm{B}$ - các hệ số phụ thuộc vào điều kiện khí quyển và điều kiện hình học

\section{b) Xây dưng hàm hồi quy và đánh giá đô} chính xác

Dữ liệu Sentinel 2A sau khi tiền xử lý ảnh được chuyển đổi từ giá trị số sang giá trị phổ, được tiến hành lọc mây và tăng cường chất lượng ảnh. Sau đó, các công cụ phân tích không gian trong phần mềm ArcGIS 10.3 được sử dụng để chiết tách các số liệu phổ theo đúng vị trí các điểm lấy mẫu cho toàn bộ các kênh phổ. Phần mềm Excel được sử dụng để chuẩn hóa các các số liệu thu được. Mối tương quan giữa các trị phản xạ phổ và giá trị độ dẫn điện của đất được thực hiện, từ đó ước tính độ mặn của đất từ dữ liệu Sentinel 2A.

Trong nghiên cứu này, ngoài tìm mối tương quan giữa $\mathrm{EC}_{1: 5}$ với các kênh phổ đơn lẻ, chúng tôi còn phân tích tương quan với các chỉ số đã được sử dụng như một công cụ đánh giá độ mặn của đất sử dụng tư liệu viễn thám (trong Bảng 1). Từ đó để xác định kênh phổ hay chỉ số phù hợp thành lập bản đồ $\mathrm{EC}_{1: 5}$ cho khu vực nghiên cứu.

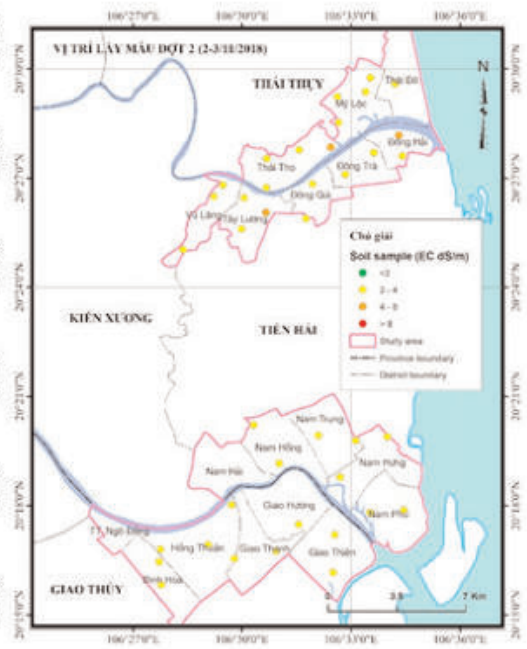

20-22/01/2018 và đơt 2 ngày 2-3/11/2018

Toàn bộ quy trình thành lập bản đồ độ mặn của đất sử dụng tư liệu viễn thám và dữ liệu thực địa được trình bày trong Hình 3 .

\section{KẾT QUẢ NGHIÊN CÚ'U}

\subsection{Mối tương quan giữa $E C_{1: 5}$ với các} kênh phổ đơn và các chỉ số

Mối tương quan giữa độ dẫn điện $\mathrm{EC}_{1: 5}$ và các kênh phổ của tư liệu dữ liệu Sentinel được thể hiện trong Hình 4. Theo đó, độ mặn có mối tương quan mạnh với kênh phổ NIR và SWIR, trong đó kênh NIR có mối tương quan lớn nhất với độ mặn của đất $(0.75)$. Những kênh phổ khác của Sentinel 2A thể hiện mối tương quan không rõ cùng với độ mặn của đất.

Tương quan giữa độ dẫn điện $\mathrm{EC}_{1: 5}$ và các chỉ số (Bảng 1) triết tách từ ảnh Sentinel 2A được thể hiện trong Hình 5 . Từ sơ đồ Hình 5 , cho thấy các chỉ số NDSI, NDVI, SAVI và SI5 có tương quan yếu với độ mặn. Ngược lại, SI4 và VSSI có mối quan hệ rõ ràng hơn với độ mặn với hệ số tương quan $\mathrm{R}^{2}$ cao hơn 0,6 .

\section{2. Ước tính và đánh giá độ chính xác ước tính độ mặn của đất}

Sau khi sử dụng phương pháp hồi quy cho năm chỉ số được tạo ra từ dữ liệu Sentinel $2 \mathrm{~A}$ bao gồm SI4, NDVI, SAVI, VSSI và NIR cho độ 
Bảng 1: Bảng các chỉ số

\begin{tabular}{|c|c|c|}
\hline $\mathrm{N}_{0}$ & Tên & Công thức \\
\hline 1 & Salinity index - SI 4 & SI4 = (Red x NIR)/Green \\
\hline 2 & Salinity index - SI 5 & SI5 = blue $/$ green \\
\hline 3 & Normalized Difference salinity index (NDSI) & NDSI = (Red - NIR) $/($ Red + NIR) \\
\hline 4 & Normalized Difference Vegetation index NDVI & NDVI $=($ NIR - Red $) /($ Red + NIR) \\
\hline 5 & Soil Adjusted Vegetation index (SAVI) & SAVI $=(1+\mathrm{L}) \times($ NIR - Red $/(\mathrm{L}+$ Red + NIR) \\
\hline 6 & Vegetation soil salinity index (VSSI) & VSSI = $2 \times$ green $-5 \times$ (Red + NIR) \\
\hline
\end{tabular}

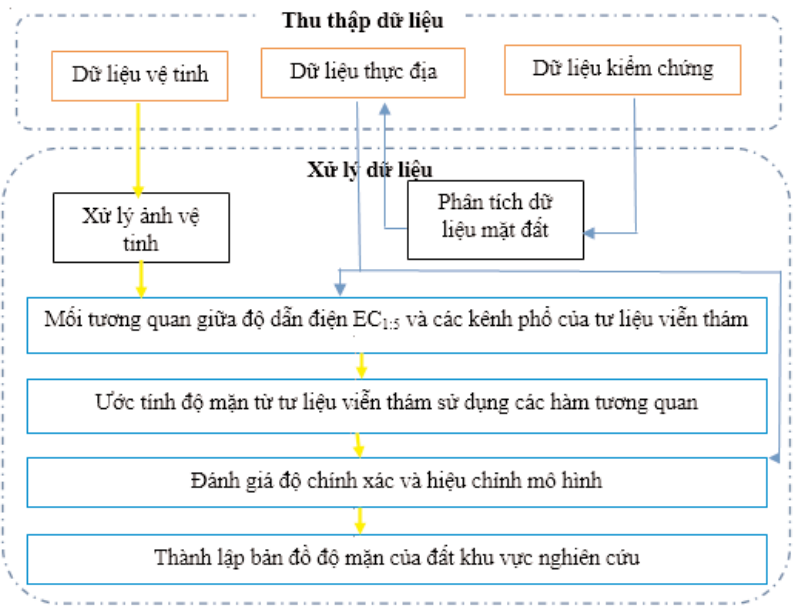

Hình 3: So đồ ước tính độ mặn của đất sử dụng tu liệu viễn thám

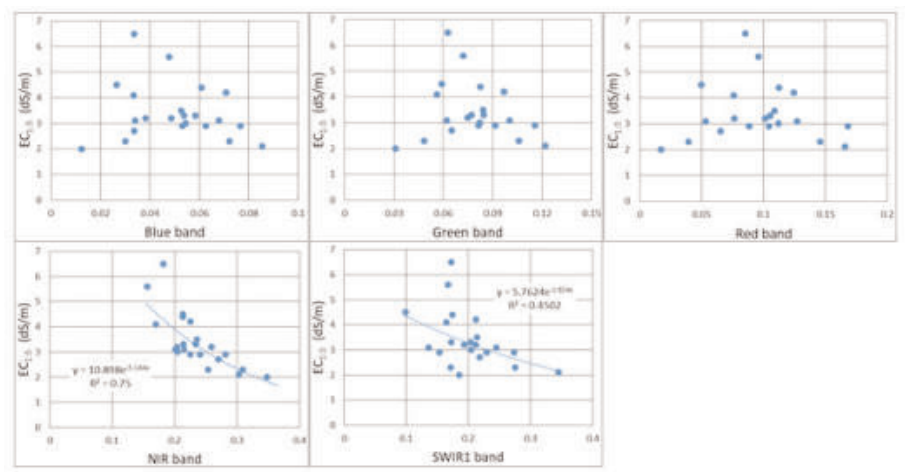

Hình 4: Mối tương quan giũa độ dẫn điện $E C_{1: 5}$ và các kênh phổ của ảnh Sentinel $2 A$

mặn của đất, kết quả tính toán cho thấy rằng các mô hình hồi quy có hệ số tương quan $\left(\mathrm{R}^{2}\right)$ cao được xác định rõ giữa độ mặn của đất hiện trường và giá trị mặn ước tính từ dữ liệu viễ̃n thám. Hệ số cao nhất là 0,75 giữa độ dẫn điện $\mathrm{EC}_{1: 5}$ và kênh phổ NIR. Bảng 2 thông kê các mô hình hồi quy để ước tính $\mathrm{EC}_{1: 5}$ từ dữ liệu viễn thám, bao gồm NIR, SI4, NDVI, SAVI và VSSI.

Các kết quả phân tích thống kê được thể hiện trong Bảng 2. Cả năm mô hình hồi quy có hệ số tương quan cao $\left(\mathrm{R}^{2}\right)$ với giá trị $\mathrm{P}$ nhỏ hơn 0,05 .
Do đó, nghiên cứu áp dụng tất cả các mô hình này để ước tính độ mặn của đất dựa trên các chỉ số viễn thám cho 50 mẫu đất thực địa. Hình 6 cho thấy có mối tương quan chặt chẽ giữa $\mathrm{EC}_{1: 5}$ ước tính và $\mathrm{EC}_{1: 5}$ thực địa khi sử dụng các mô hình NIR và VSSI với hệ số tương quan lần lượt là 0,74 và 0,67 . (Xem bảng 2, hình 6)

\subsection{Kết quả lập bản đồ độ mặn ước tính}

Kết quả dánh giá độ chính xác cho thấy độ mặn $\left(\mathrm{EC}_{1: 5}, \mathrm{dS} / \mathrm{m}\right)$ có mối tương quan cao nhất 


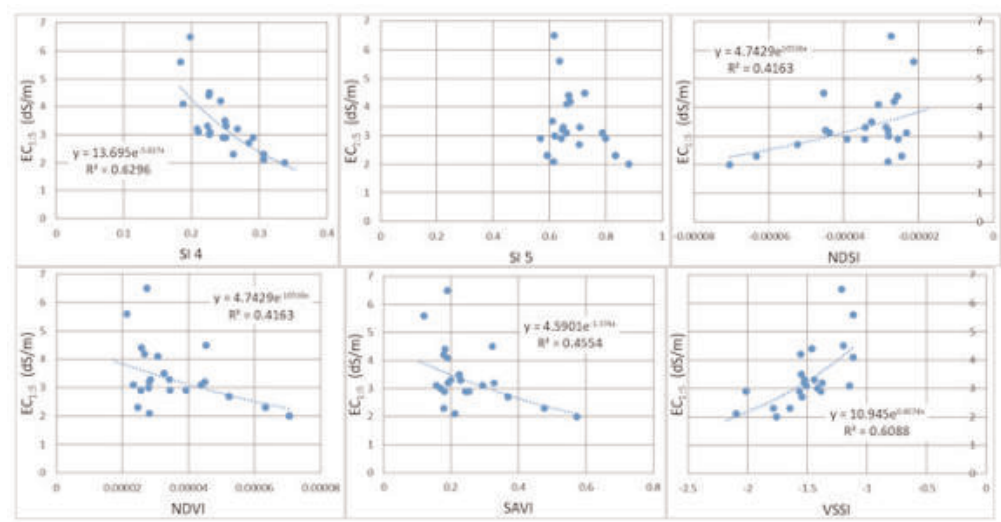

Hình 5: Mối tuoong quan giũa độ dẫn điện $E C_{1: 5}$ và các chỉ số

Bảng 2: Mô hình hồi quy để ước tính EC tù dũ liệu viễn thám

\begin{tabular}{|c|c|c|c|c|}
\hline $\mathbf{N}_{\mathbf{0}}$ & Phương trình hồi quy & $\mathbf{R}^{2}$ & $\mathbf{P}$ & Độ lệch chuẩn \\
\hline 1 & $\mathrm{y}=10.898 \mathrm{e}^{-5.144^{*} \mathrm{NIR}}$ & 0.75 & 0.00021 & 3.8 \\
\hline 2 & $\mathrm{y}=4.7429 \mathrm{e}^{-10538^{*} \text { NDVI }}$ & 0.42 & 0.0003 & 2.96 \\
\hline 3 & $\mathrm{y}=4.5901 \mathrm{e}^{-1.374^{*} \text { SAVI }}$ & 0.46 & 0.00032 & 3.23 \\
\hline 4 & $\mathrm{y}=10.945 \mathrm{e}^{0.8074^{*} \text { VSSI }}$ & 0.61 & 0.00015 & 2.87 \\
\hline 5 & $\mathrm{y}=13.695 \mathrm{e}^{-5.827^{*} \text { SI }} 4$ & 0.63 & 0.00076 & 3.56 \\
\hline
\end{tabular}

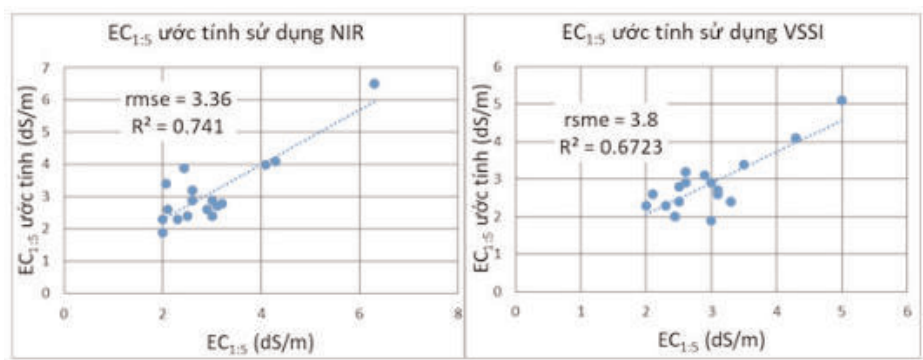

Hình 6: Mối tương quan $E C_{1: 5}$ ước tính tù̀ Sentinel $2 A$ và $E C_{1: 5}$ của 29 mâu đất thực địa

với các chỉ số NIR. Do đó, nghiên cứu này sử dụng các hàm hồi quy NIR để thành lập bản đồ độ mặn của đất cho khu vực nghiên cứu. Độ mặn của đất được phân thành năm cấp dựa trên Chhabra (1996) và Skagss (2014). (Xem hình 7)

\subsection{Thảo luận}

Khu vực nghiên cứu có đặc điểm là vùng đồng bằng thấp ven biển nên bị ảnh hưởng bởi thủy triều và nước biển dâng. Nước biển xâm nhập vào nội địa qua sông khi thủy triều lên cao hoặc đê biển bị vỡ do bão. Nước mặn cũng có thể lấn sâu vào đất liền bởi các mao mạch, vết nứt trong đất. Đây là cơ chế chính của quá trình nhiễm mặn ở khu vực nghiên cứu. Mục đích của nghiên cứu này là lập bản đồ phân chia không gian độ mặn của đất để hỗ trợ quản lý và lập kế hoạch nông nghiệp. Do đó, các mẫu được lấy ở độ sâu dưới $5 \mathrm{~cm}$ tương ứng với hầu hết các vùng rễ của cây.

Kết quả nghiên cứu chỉ ra rằng độ mặn của đất có mối quan hệ chặt chẽ với hệ số phản xạ tại kênh NIR. Điều này phù hợp với nhiều nghiên cứu khác nhau. Kết quả đánh giá độ chính xác của mô hình cũng cho thấy tương quan cao giữa kênh phổ ở dải sóng cận hồng ngoại nhiệt với độ mặn trong khu vực nghiên cứu. Chúng được thể hiện qua sự tương đồng giữa kết quả ước tính và số liệu thực địa (với $\mathrm{R}^{2}=0,74$ và $\mathrm{RMSE}=3.36$ $\mathrm{dS} / \mathrm{m}$ ). Điều tương tự cũng được tìm thấy đối với chỉ số VSSI (với $\mathrm{R}^{2}=0,67$ và $\mathrm{RMSE}=3.8$ 

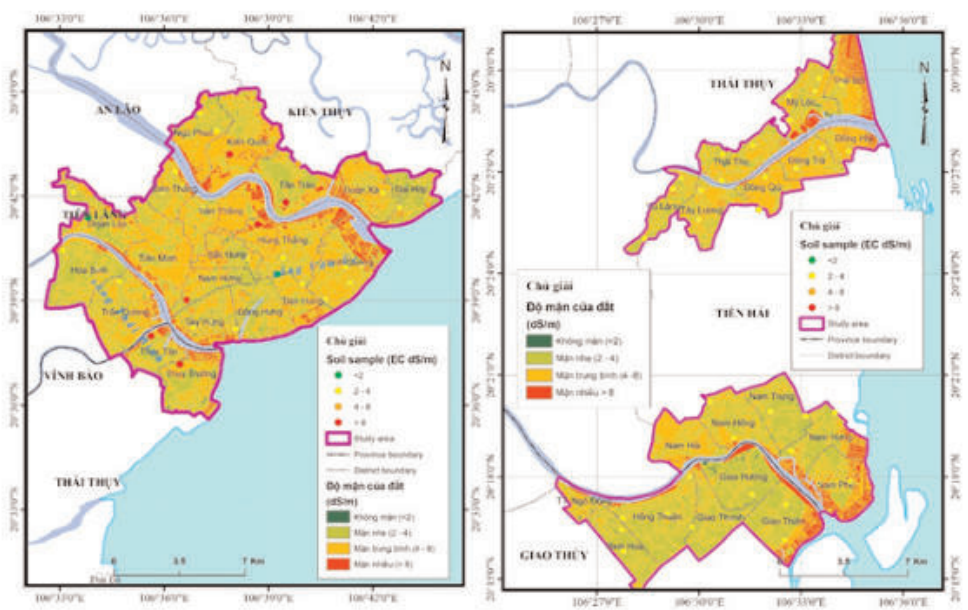

Hình 7: Bản đồ độ mặn đất ước tính tù dũ liệu Sentinel 2 A sủ dụng mô hình hồi quy NIR

$\mathrm{dS} / \mathrm{m})$. Điều này cho thấy kênh NIR và chỉ số VSSI phù hợp để ước tính độ mặn của đất cho khu vực ĐBSH.

Trong nông nghiệp, muối không được hấp thụ ở bề mặt, thay vào đó muối được tích lũy ở phần dưới của vùng rễ. Do đó, khi độ mặn tồn tại trên bề mặt, nó có thể được phát hiện thành công với công nghệ viễn thám. Cơ chế giám sát này dựa trên hoạt động quang hợp của thực vật (tăng phản xạ trong dải sóng nhìn thấy và giảm phản xạ trong dải sóng cần hồng ngoại nhiệt). Về cơ bản, nghiên cứu này nhằm xác định mối quan hệ trực tiếp giữa độ mặn của lớp đất mặt và độ phản xạ quang phổ. Trong trường hợp của khu vực nghiên cứu, đất bị ảnh hưởng bởi muối được mang từ biển bởi thủy triều và mực nước biển dâng cao. Vì lý do này, các khu vực bị ô nhiễm bởi muối do độ cao thấp và bị ngập bởi dòng chảy thủy triều thể hiện độ phản xạ thấp hơn trên kênh NIR so với các khu vực khác.

Trong tương lai, cần phải mở rộng phạm vi nghiên cứu dựa trên việc theo dõi độ mặn của đất trong thời gian dài để hiểu rõ hơn về sự tương tác giữa các điều kiện tự nhiên (độ ẩm đất, loại đất, v.v.) và tác động của con người (thủy lợi, sử dụng đất, v.v.). Những tương tác tự nhiên và con người này sẽ dẫn đến ô nhiễm đất và có thể phát hiện bằng các hình ảnh viễn thám. Điều này rất có giá trị đối với xác định độ mặn của đất nông nghiệp trên toàn thế giới, vì phương pháp này có chi phí thấp và độ chính xác chấp nhận được.

\section{Kết luận}

Kết quả nghiên cứu cho thấy rằng việc sử dụng tư liệu vệ tinh Sentinel 2A cho phép ước tính giá trị độ mặn của bề mặt đất với độ chính xác chấp nhận được. Trong đó, các kênh phổ NIR và VSSI có tương quan cao với độ dẫn điện $\mathrm{EC}_{1: 5}(\mathrm{dS} / \mathrm{m})$ với hệ số tương quan tương ứng là 0,75 và 0,63 , trong khi một số kênh phổ còn lại tương quan thấp với độ dẫn điện (với hệ số tương quan nhỏ hơn 0.4 ). Kết quả đánh giá độ chính xác cũng cho thấy việc ước tính độ mặn của đất có độ chính xác cao đối với đất có độ mặn thấp và có độ chính xác thấp đối với đất có độ mặn cao. Điều đó phản ánh đúng bản chất tương tác giữa các tinh thể muối với sóng điện từ.

Có một thực tế rằng biến đổi khí hậu đang ảnh hưởng đến các tỉnh của ĐBSH qua nước biển dâng, xâm nhập mặn và hạn hán dẫn đến tăng độ mặn của đất ở các khu vực nghiên cứu, đặc biệt là ở các địa hình thấp, như khu vực ven biển và cửa sông. Do đó, việc canh tác nông nghiệp ở những vùng cửa sông sẽ bị thay đổi. Các biện pháp thích hợp để cải thiện các tác động của việc tăng độ mặn của đất phải được thực hiện để duy trì sự phát triển kinh tế và nông nghiệp của vùng. 
Mô hình mà nghiên cứu đề xuất phù hợp áp dụng cho các khu vực ven biển khác để đánh giá tính dễ bị tổn thương của đất đối với xâm nhập mặn ở quy mô khu vực với chi phí thấp và độ chính xác chấp nhận được. $\bigcirc$

\section{Lời cảm ơn}

Nghiên cứu này được thực hiện với sự giúp đỡ của Đề tài "Xác định mức độ nhiếm mặn tầng đất mặt canh tác nông nghiệp ở một số vùng gần cưa sông ven biển Hải Phòng - Thái Bình bằng ảnh viê̂n thám siêu phổ", mã số VAST01.02/1718 thuộc Đề tài, dự án, nhiệm vụ KHCN cấp Viện Hàn lâm KHCNVN

\section{Tài liệu tham khảo}

[1]. Dehni A, Lounis M (2012). Remote sensing techniques for salt affected soil mapping: application to the Oran region of Algeria, Procedia Eng., 2012; vol. 33: 188-198.

[2]. Fernandez-Buces N, Siebe C, Cram S, Palacio JL (2006) Mapping soil salinity using a combined spectral response index for bare soil and vegetation: a case study in the former lake Texcoco. Mexico. J. Arid Environ. 65:644-667

[3]. Madani AA (2005) Soil salinity detection and monitoring using Landsat data: a case study from Siwa Oasis. Egypt. Gisci. Remote Sens 42:171-181

[4]. Metternicht G, Zinck A (2008) Remote sensing of soil salinization: impact on land management, CRC Press; ISBN 9781420065022.

[5]. Richards LA (1954) Diagnosis and improvement of saline and alkali soils. U. S. Dept. Agric. Handbook

[6]. Tiêu chuẩn Việt Nam TCVN 6650:2000 (ISO 11265:1994) về chất lượng đất - Xác định độ dẫn điện riêng do Bộ Khoa học Công nghệ và Môi trường ban hành

[7]. Verma KS, Saxena RK, Barthwal AK, Deshmukh SN (1994) Remote sensing technique for mapping salt affected soils. Int. J. Remote Sens 15(9):1901-1914. 0

\section{Summary}

Estimating soil salinity of agricultural soil in some areas near the estuaries of Hai Phong Thai Binh provinces using Sentinel 2A imagery

Le Thi Thu Hien, Nguyen Thanh Binh, Nguyen Ngoc Thang, Institute of Geography, Vietnam Academy of Science and Technology

\section{Pham Minh Hai, Vietnam Institute of Geodesy and Cartography}

In recent years, the complexity of the downstream flow in dry season in combination with the increasing demand for water of different economic sectors... has led to the increasing salinity intrusion in some coastal areas of the Red River delta. This study evaluated soil salinity at the estuaries of the Van Uc, Thai Binh and Tra Ly rivers using Sentinel 2A data. Sentinel 2A data were used to extract indices including single spectral band, VSSI, SAVI, NDVI, and NDSI index. Statistical analyses between conductivity $\left(\mathrm{EC}_{1: 5}, \mathrm{dS} / \mathrm{m}\right)$ and indices were performed. The results show that the spectral values of the near infrared band and the VSSI index strongly correlate with $\mathrm{EC}_{1: 5}$ (with correlation coefficients of 0.75 and 0.63 , respectively). The comparison shows that the soil salinity estimated from Sentinel 2A data is consistent with field data (with $\mathrm{R}^{2}=0.74$ and $\mathrm{RMSE}=3.36 \mathrm{dS} / \mathrm{m}$ for the spectral band NIR and $\mathrm{R}^{2}=0,67$ and RMSE $=3.8 \mathrm{dS} / \mathrm{m}$ for the VSSI index). The results of this study demonstrate that Sentinel 2 A data has high potential for monitoring the salinity of the topsoil. Moreover, the study results are useful for agricultural activities, providing important information to authorities and farmers by mapping soil salinity as a basis for better crop choices to reduce economic losses in the context of climate change. $\bigcirc$ 